\title{
Innovation and regional economic resilience: an exploratory analysis
}

\author{
Gillian Bristow $^{1}$ (D) Adrian Healy ${ }^{1}$
}

\begin{abstract}
The varying rates of recovery of European regional economies from the 2007 to 2008 economic crisis have raised interesting questions about the sources of economic resilience. Policy discourse has increasingly asserted the role played by innovation in facilitating rapid recovery from economic shocks, whilst evolutionary thinking has highlighted the specific importance of innovation capacity. However, empirical evidence on this is lacking. This paper addresses this gap by providing new empirical analysis of the relationship between regional innovation capacity and the resilience of European regions to the crisis. It finds that regions identified as Innovation Leaders at the time of the crisis were significantly more likely to have either resisted the crisis or recovered quickly from it (i.e. within 3 years). This provides important insights for evolutionary approaches theorising the relationship between innovation and resilience.
\end{abstract}

JEL Classification R1 - O3

\section{Introduction}

The economic crisis of 2007-2008 heralded the most severe economic downturn in the history of the European Union (EU). Studies of the impact of the crisis have shown that regional economies have experienced wide differences in their ability to recover

$凶$ Gillian Bristow

Bristowg1@cardiff.ac.uk

Adrian Healy

HealyA2@cardiff.ac.uk

1 School of Geography and Planning, Cardiff University, Glamorgan Building, King Edward VII Avenue, Cardiff CF10 3WA, UK 
from it (Hadjimichalis and Hudson 2014). This has prompted increasing scholarly interest in the notion of regional economic resilience-the ability of regions to resist and/or recover quickly from shocks — as well as the factors influencing it (Bristow and Healy 2014; Martin and Sunley 2015; Capello et al. 2015; Sensier et al. 2016).

Policy makers and champions of business innovation have been keen to assert the critical importance of firm innovation in resilience to economic shocks. In the midst of the crisis, for example, a prominent UK innovation body argued that innovation was critical for enabling economies to recover from recessions (NESTA 2009), whilst in 2014 the UK Government's Department for Business, Innovation and Skills (BIS) asserted that 'innovation builds resilience and a dynamic economy' (UK BIS 2014a, p. i). This is also evident in European Union (EU) policy discourse, with advice provided to the European Commission in 2014 strongly asserting that innovation is critical to enabling economies to be more crisis resilient (SC6 Advisory Group 2014). A growing body of work has also highlighted the importance of innovation as critical to the long-term regional path renewal and restructuring processes that enable regions to adapt their industrial and technological structures over time to changes in the economic landscape (e.g. Cooke et al. 2012; Simmie 2014a, b; Wolfe 2014; Wolfe and Gertler 2016). However, as Sunley (2013) has pointed out, to date there is very little empirical evidence as to whether those regional economies which are deemed to be more innovative are more likely to be resilient and able to weather an economic shock or recover quickly when a crisis occurs. Instead, the relationship between innovation and resilience to a shock tends to be implicitly assumed. This relationship thus needs more investigation, particularly if we are to be more conclusive about how and why successful regional innovation systems should be fostered and supported, and if we are to better understand what is important for regional resilience.

Exploring the relationship between innovation and resilience more fully poses a number of challenging conceptual and empirical questions however, particularly surrounding how innovation is conceived, measured and defined for these purposes. In regional development literatures, innovation is subject to a diversity of definitions and interpretations (Moulaert and Sekia 2003). Innovation may be defined and measured narrowly in terms of research and development or technological innovation, which is associated with the development of new products and processes. This has some appeal for understanding resilience not least because of the growing body of international evidence at the microscale which shows that firms which invest more in research and development tend to perform better than their non-innovative counterparts through crises and have better long-term survival rates (Coad 2009; Roper and Xia 2014; UK BIS 2014a,b). This also resonates with the Schumpeterian view of innovation as a driver of economic change which sees it as a major disrupter of production functions and a source of long-term economic transformation (Schumpeter 1939, 1942).

However, a narrow, technological definition of innovation and its manifestation through new products and processes may not be sufficient when seeking to understand the ability of regions to resist and respond to an economic crisis in the short-term. Given the infrequent introduction and diffusion of radical, disruptive innovations on regional economies, evolutionary economic geographers have made a distinction between resilience based on adaptation (the tendency to replicate and reproduce existing economic activities and ways of working) and adaptability (characterized 
by a dynamic capacity to develop and pursue new economic trajectories) (Grabher and Stark 1997; Pike et al. 2010). The differences between the two have significant implications for the relative economic resilience of regional economies in the face of unexpected economic shocks, with those places able to effect greater adaptability regarded as exhibiting greater resilience (Simmie and Martin 2010).

The nature and source of adaptability in regions would thus appear to be key to resilience, with evolutionary economic geographers increasingly asserting that is the innovation capacity of regions or their capacity to continually reinvent themselves and break from their past that is central to this adaptability (Simmie 2014a; Xiao et al. 2016). This innovation capacity, if not yet clearly defined, is conceived broadly as embracing both the effective social, organizational and institutional capacities for innovation in a region, as well as its technological research and development (Isaksen and Trippl 2014; Xiao et al. 2016). In doing so, it moves beyond traditional conceptions of innovation as science and technology-led, to embrace conceptions that emphasize experiential learning through doing, using and interacting (Jensen et al. 2007). To date, however, there has been no systematic empirical analysis as to whether those regions with measurably higher levels of innovation capacity were more resilient to the recent economic crisis in Europe.

The purpose of this paper is to address this gap. More specifically, it seeks to investigate the relationship between innovation and regional economic resilience in two main ways. Firstly, the paper seeks to develop new empirical insights into the relationship between regional innovation capacity and resilience. We do this by drawing upon data from the European Commission's Regional Innovation Scoreboard and a novel measure of the resistance and recovery of European regions to the 2007-2008 economic crisis. We present some initial findings and consider what these reveal about both the relationship between innovation and resilience, and the challenges of empirically measuring adaptive processes in regions and the dynamic interactions which shape them.

Secondly, it seeks to reflect upon and contribute to current conceptual understanding of the dynamic processes shaping the relationship between regional innovation and resilience to system-wide economic shocks. The paper explores evolutionary approaches to conceptualizing the relationships between innovation and regional resilience which tend to emphasize the Schumpeterian view of the role of innovation as ostensibly disruptive and providing an evolutionary path out of crisis through acting as a source of novelty in terms of products, processes and ultimately economic structures. The paper critically reflects upon this perspective and draws upon complex adaptive systems thinking to explore the potentially more incremental and adaptive role innovation may play in crisis resistance and recovery. This paper is thus exploratory in nature, but is intended to help enhance thinking about the relationship between innovation and resilience, and to act as a stimulus to further debate.

The paper is now organized as follows. The next section seeks to problematize the role that innovation plays in regional economic resilience by critically reflecting upon how current evolutionary thinking conceives of these concepts and their relationship. Section three outlines our methodological approach to investigating the relationship between innovation in European regions and their ability to demonstrate resilience to the recent economic crisis, whilst section four seeks to explore and explain the patterns 
observed. We conclude by reflecting on the implications of these findings for both evolutionary thinking on regional resilience and adaptability, and policy approaches that may enhance them.

\section{The role of innovation in resilience: an evolutionary perspective}

Recent economic crises have prompted increasing scholarly interest in the notion of resilience in an effort to analyse and understand differences between regions in their vulnerability to economic shocks (Bristow and Healy 2014; Martin and Sunley 2015; Capello et al. 2015; Sensier et al. 2016). In the evolutionary economic geography literature, there is an emerging consensus that regional economic resilience may be defined as the capacity of a regional or local economy to withstand, recover from and reorganize in the face of market, competitive and environmental shocks to its developmental growth path (Bristow and Healy 2014, 2015; Boschma 2015; Martin and Sunley 2015). As such, there is increasing understanding that resilience is a complex, multi-dimensional property of regional economic systems embracing resistance (the ability of regions to resist disruptive shocks in the first place); recovery (the speed of return to some pre-shock performance level); reorientation (the extent to which the region adapts its economic structure); and renewal (the degree to which the region resumes its pre-shock growth path) (Martin 2012; Martin and Sunley 2015).

The relationships between these different dimensions of resilience are not yet well understood however, and they may not necessarily be coupled or mutually exclusive (Cowell et al. 2016). For example, a region may experience rapid bounce-back in terms of output and income after a shock and yet its recovery may be based on existing sources of knowledge and technologies such that it may not develop sufficient opportunities to adapt or upgrade its industrial and technological structure to the future challenges confronting its firms and workforce (Simmie and Martin 2010). Another possibility is that a region which exhibits resistance or recovery is exhibiting precisely the sort of adaptive capacity that is critical for its long-term transformation, i.e. its ability to respond to shocks and demonstrate adaptation may be constitutive of its capacity to develop new growth paths and demonstrate adaptability (Boschma 2015). This hints at both the importance of understanding both the nature of the shock for a region's existing industrial structures and capacities, and also the nature and source of adaptability in regions and its role in resistance and recovery processes.

The importance of innovation for long-term economic growth and regional development is well established. Innovation, defined as the capacity to produce new products and processes coupled with their dissemination and widespread use, has long been regarded as critical to the economic dynamism of any territory (Crescenzi 2011). This is because innovation tends to be associated with lasting 'endowment effects' associated with higher rates of capital accumulation by firms, higher real wages for people and higher regional per capita incomes that diverge substantially from other regions for long periods of time (Storper 2011, p. 339). However, the relationships between innovation and regional economic performance are complex and subject to a wide range of approaches (Crescenzi 2011). 
Evolutionary economic geographers have increasingly highlighted the importance of innovation in the evolutionary dynamics of regional economies (Cooke 2012; Simmie 2014b). Various strands of evolutionary theorizing have been developed in an effort to provide a more specific understanding of the role of innovation in regional economic evolution and resilience. The work of evolutionary economist Schumpeter $(1939,1942)$ has been widely drawn upon in developing the notion that technological innovation is one of the key drivers of adaptive processes and thus resilience. Schumpeter identified that capitalist economies are characterized by a four-phase cycle of prosperity, recession (a period of economic decline following prosperity), depression (a period of below zero decline) and recovery (the return of positive growth). He posited that accelerated technological innovation through the period of depression acted as the main driver of recovery. He also argued that recession and depression serve to destroy some outmoded or unproductive sectors through gales of creative destruction, thereby creating opportunities for the development of new sectors and phases of growth (Simmie and Martin 2010; Simmie 2014b). Innovation is thus conceived in relatively narrow terms as ostensibly a technological process with the capacity to disrupt and transform.

A developing body of work within evolutionary geography has highlighted the importance of technological innovation in the reorientation and renewal dimensions of resilience through its role in facilitating the adaptability of the region's industrial structure (Boschma 2015). Technological innovation is regarded as critical in enabling regions to continually branch out of existing specialized industrial sectors and develop more diversified economies (Simmie and Martin 2010; Isaksen and Trippl 2014). Indeed, a range of studies have demonstrated the importance played by the recombination of knowledge in overlapping technological fields_related variety —in long-term regional adaptability and new path creation (Frenken et al. 2007; Boschma et al. 2013). It has been claimed, for example, that California's Silicon Valley exemplifies a region which has bounced back from the aftermath of the internet bubble crash by developing biotech and cleantech as a source of continuous growth (Cooke 2011). Other studies have suggested that the development of new, unrelated activities is also critical for adaptability however, as regions with unrelated variety are more likely to produce technological breakthroughs (Castaldi et al. 2013; Boschma 2015). There has been much less interrogation of the role of technological innovation in the resistance and recovery dimensions of resilience although there is some evidence that related variety can act as a shock absorber for sector-specific shocks in certain circumstances, notably where skills can apply across related industries. This is because the redundant employees can more easily find jobs in a region where other industries may make use of their skills (Diodato and Weterings 2014). This also prevents the destruction of human capital in a region as well as the outflow of highly skilled people to other regions (Boschma 2015).

Schumpeterian thinking on the broader conceptual patterns and cycles of creative destruction and resilience has been developed by Simmie and Martin (2010). They have drawn upon the panarchy model developed by Gunderson and Holling (2002) to understand how crises may lead to innovation and new development trajectories. Simmie and Martin's four-phase adaptive cycle model of regional economic resilience postulates that in regional economies, adaptation follows a sequential cycle. A period 
of rapid expansion and growth ultimately increases the connectedness between the various components of the regional economy such that the pattern of development becomes increasingly rigid. Its resilience to potential shocks declines leading to creative destruction and a phase of resource release. This opens up the possibility for re-organization characterized by innovation, experimentation and restructuring, as new types of activity begin to emerge. Connectedness is low, and the potential for the creation of new paths is high. As the particular forms of new activity and new technologies are exploited, new comparative advantages develop, resilience is increased and a new round of regional growth and accumulation is set in motion. Simmie and Martin (2010) acknowledge that this model may have some limitations not least in its implication that regional economic development necessarily follows these cycles and has an ineluctable inner logic.

Different insights into the potential role of innovation in regional economic evolution and resilience emerge when regions are conceived more broadly as complex adaptive systems. Complex adaptive systems (CAS) thinking considers that the world is composed of systems that are constantly adapting. Thus, complexity arises from the interrelationships, interaction and interconnectivity of elements within a system, and between a system and its environment. There is no dichotomy between a system and its environment in the sense that the system always adapts to a changing environment. Rather the system is closely linked with all other related systems making up an ecosystem. Within such a context, change is viewed in terms of co-evolution with all other related systems, rather than as adaptation to a separate and distinct environment (Martin and Sunley 2006; Berkes and Folke 1998; Cooke and Eriksson 2011).

This finds resonance with evolutionary economic geographers who understand regional economies to be characterized by nonlinear and non-equilibrium dynamics which 'evolve and move along open-ended developmental trajectories with an unknown end-point' (Hudson 2010, p. 13). This nonlinearity creates path dependence or local rules of interaction which means outcomes evolve as a consequence of the region's own history, and elements of emergence whereby macrolevel structures or patterns of behaviour arise endogenously and spontaneously out of the microlevel interactions of economic agents and their environment (Martin and Sunley 2012). In short, regional economies are 'marvels of complexity' (Beinhocker 2007, p. 6), characterized simultaneously by both order and complexity and shaped by the dynamic interactions of economic agents (i.e. firms, households, governance actors) and their changing economic environment (Bristow and Healy 2015).

CAS thinking suggests that innovation is a critical adaptive behaviour in regional economies which consist of collections of agents who are continually learning and adapting to their environment even in the absence of major shocks and disturbances (Martin and Sunley 2007). Thus, knowledge about the environment and how it is changing is the key to self-organization and the ability of entities to understand how and in what ways they need to adapt in order to survive (Cooke 2012). What distinguishes economic and human systems from biological ones is the role played by the deliberate acquisition of knowledge. Economic agents are proactive as well as reactive in implementing novel plans to access new energy sources or increase exploitation of old ones. The decay of old investments can variously be planned for (through planned depreciation) and overlooked (depending on commitment levels to specialist organi- 
zational structures or market niches). Creativity and innovation thus play an integral role in system dynamics and indeed may be regarded as the 'evolutionary fuel' of complex systems (Cooke 2012). However, this implies a broader conception of innovation capacity, i.e. one which not only embraces technological development, but also how innovation is used and applied in effecting continuous, adaptive change such as in how existing resources are used, as well as in organizational structures and strategies.

CAS thinking suggests that simple cause and effect relationships are unlikely to hold in the dynamics of complex systems and that sophisticated feedback loops are at work (Boschma 2015). There is indeed evidence that the relationship between innovation and economic growth is nonlinear (D'Agostino and Scarlato 2015). Furthermore, the adaptive cycles model does not explain the causes of each phase of adaptation nor does it take into account the continuous learning and adaptation of the constituent agents in regional economies as highlighted by CAS thinking. Crucially, for concepts of resilience, economic shocks can act to shift the mix of possibilities or change the fitness surface as described by evolutionary theorists (Cooke 2012). This can close down existing possibilities whilst opening up new opportunities. What differentiates the successful firm from the unsuccessful is their ability to respond to their changing circumstances or to take advantage of the fact that their environment and circumstances have changed.

In summary, an evolutionary perspective suggests that a regional economy's resilience to an economic shock is likely to be multi-dimensional and that it is important to distinguish between resilience as short-term resistance and recovery, and longerterm renewal and reorientation. Whilst there is increasing acknowledgement of the critical role played by technological innovation in fuelling renewal and reorientation, much less is known about the importance and nature of the relationship between innovation and the resistance and recovery of regions to an economic shock. However, evolutionary thinking suggests it has the potential to be significant since innovation provides significant potential for some shock absorption, particularly when certain sectors are hit. Furthermore, as key adaptive agents, firms have the potential capacity to exploit available knowledge and search for new opportunities when their economic environment changes. These responses are likely to be highly contingent however, and their outcomes in terms of shock absorption for the region dependent upon an array of capacities in the broader regional economic environment. These include the adaptive behaviour of other agents in the economy as well as the uptake and absorption of both technological and other forms of innovation. This raises interesting questions concerning how to measure the relationship between these broader innovation capacities and resilience as resistance and recovery. It is to this challenge that this paper now turns.

\section{Resilience and innovation: methodology and empirical analysis}

Our focus here is on the development of a method to assess the relationship between innovation and resilience in European regions to the 2007-2008 economic crisis. We do this through coupling two distinct datasets. The first has been developed by the authors to establish the resilience of European regions to the economic crisis. The 
second makes use of the results of the European Commission's Regional Innovation Scoreboard (European Commission 2012).

We develop an approach which focuses on measuring resilience in terms of postshock outcomes, but which adapts available methods for dating regional business cycles to capture more effectively differences in both the timing of when the shock hit regions, and the amplitude and duration of both the downturns experienced and subsequent recoveries. We treat each region as a separate time series and date the individual business cycle turning points. This allows us to gauge resilience by measuring how much output or employment is lost over downturns, and to calculate the time to recovery. We focus on the classical business cycle which measures absolute falls in employment rather than deviations around a trend. This allows us to measure the sensitivity of regions to economic shocks and assess crisis impacts. The approach is applied to annual employment data for the period 2001-2011. This ensures that all turning points are identified, including those of early entrants to the crisis, providing a longer picture of evolutionary employment dynamics in regions. The approach is novel in that it is the first time to our knowledge that the resilience of regions to the economic crisis has been calculated at the individual level of each region across Europe. The dataset was compiled from data provided by Cambridge Econometrics and Experian plc for the 28 countries of the EU plus Switzerland, Norway, Lichtenstein and Iceland at the NUTS 1, NUTS 2 and NUTS 3 scales. A full description of the methodology adopted can be found in Sensier et al. (2016).

The value of estimating the resilience of each individual region is that it allows us to identify when each region reaches its peak level of economic activity, when the downturn begins, when the trough associated with that downturn occurs and, crucially, at what point economic activity levels recover to their pre-crisis peak. This is significant as not all regions entered the economic crisis in the same year nor recovered at the same point in time, which can create analytical challenges if common dates for the onset of the crisis, such as 2008, are used. Following Martin (2012), we focus on absolute resilience - that is whether an economy resisted the economic shock, recovered from the economic shock or has yet to recover from the economic shock-rather than measures of resilience relative to other economies.

We have chosen to make use of employment data as this is a direct indicator of how an economy responds to an economic shock (see Sensier et al. 2016), compared to alternative measures of resilience that have been used by other authors (Davies 2011; Dubé and Polèse 2016). This is partly because social and political preferences tend to value employment as a reflection of the health of an economy, although official statistics tend to privilege GDP (Sensier et al. 2016). It also reflects the possibility that strong innovation performance of an economy might lead to the shedding of labour whilst increasing overall levels of GDP. Were this to occur as a response to an economic shock, observers could potentially argue that the economy had not been resilient to the crisis, owing to the poor employment performance of the economy. Use of an employment measure for resilience overcomes this potential outcome as innovation (as commonly measured) does not tend to lead to employment gains in conjunction with falling levels of GDP. 
We have chosen to make use of NUTS 2 data both for policy reasons, as this is the level most commonly used for regional analysis, and because this is the scale at which data on innovation performance is reported (European Commission 2012, 2014).

For this analysis, we have taken the approach of defining resilience as the ability of an economy to resist a shock and maintain existing levels of economic activity, in this case employment levels, or to recover to the pre-shock peak within a given period of time. We have followed a convention that resilient regions will have recovered to their peak levels within 3 years of the onset of a downturn. This approach therefore allows us to identify which regions recovered quickly from the crisis and those which did not recover at all or showed a slower rate of recovery. Resilient regions then are those that either did not experience a downturn in employment following the global economic shock (Resistant) or those that experienced a downturn in employment but recovered to pre-shock peak levels by 2011 (Recovered). Regions that were not resilient to the crisis are those that have not recovered to pre-shock peak levels by 2011, and this category is subdivided into two further categories: those that have registered an upturn in employment but had not recovered to their pre-shock peak by 2011 (Not Recovered: Upturn) and those that were still to record an upturn in employment by 2011 (Not Recovered: Downturn).

Measuring regional innovation performance across the EU is notoriously difficult owing to limitations in data availability and the complexity of the innovation process (Bruijn and Lagendijk 2005; Navarro et al. 2009). In an attempt to develop a common statistical approach, academics at UNU-MERIT compile a Regional Innovation Scoreboard on behalf of the European Commission (2012). Reporting approximately every 3 years (2006, 2009, 2012, 2014), the Regional Innovation Scoreboard is a composite measure formed from 12 indicators that are judged to provide a direct or indirect measure of the innovation performance of a region (Table 1). Broadly, these indicators

Table 1 Composition of the Regional Innovation Scoreboard. Source: European Commission (2012, 2014)

\begin{tabular}{|c|c|}
\hline \multirow[t]{3}{*}{ Enablers of innovation } & Population with tertiary education per 100 population aged $25-64$ \\
\hline & Public R\&D expenditures (\% of GDP) \\
\hline & $\begin{array}{l}\text { Employment in knowledge-intensive services + Employment in } \\
\text { medium-high/high-tech manufacturing as } \% \text { of total workforce } \\
\text { (\% of total workforce) }\end{array}$ \\
\hline \multirow[t]{6}{*}{ Innovation activity } & Business R\&D expenditures (\% of GDP) \\
\hline & Non-R\&D innovation expenditures ( $\%$ of total turnover) \\
\hline & SMEs innovating in-house (\% of all SMEs) \\
\hline & Innovative SMEs collaborating with others (\% of all SMEs) \\
\hline & Public-private co-publications \\
\hline & EPO patent applications per billion GDP (in PPP€) \\
\hline \multirow[t]{3}{*}{ Innovation outputs } & Technological (product or process) innovators (\% of all SMEs) \\
\hline & $\begin{array}{l}\text { Non-technological (marketing or organizational) innovators } \\
\text { (\% of all SMEs) }\end{array}$ \\
\hline & $\begin{array}{l}\text { Sales of new to market and new to firm innovations as } \% \text { of turnover } \\
\text { (\% of total turnover) }\end{array}$ \\
\hline
\end{tabular}


attempt to capture the enablers of innovation in a region, levels of innovation activity and the outputs of that activity (European Commission 2014). The enablers of innovation consider the drivers of innovation in a region external to the firm, focusing on human resources and public support for Research and Development (R\&D). Data for each of these are taken from Eurostat sources. Innovation activity outputs make use of returns from the Community Innovation Survey (CIS), providing an estimate of firm-level innovation activity across EU regions, alongside Eurostat data on patent applications and R\&D expenditures at the firm level. The data include measures on collaboration and co-publications, which may indicate the strength of social capital ties, an emerging consideration in the field of resilience (Aldrich and Meyer 2014). Innovation outputs capture the effects of innovation activities reported by firms through the CIS, in particular the percentage of firms reporting innovation outputs and the sale of new goods and services. This has the advantage of ensuring that the composite index considers the outputs of the innovation process within a region, rather than simply focusing on inputs such as patent applications as is the case with many analyses. Whilst the Regional Innovation Survey has its limitations, its strengths as a measure of the broader capacity for innovation within a region, together with its availability on a comparable basis across the EU, make it a particularly valuable source of data for our purposes.

We have used data from the 2012 Scoreboard as the data collection for this paper covers the period coinciding with crisis (taking 2008 as the average turning point across Europe) or its immediate aftermath. We have selected this timeframe as we are interested in whether the innovation capacity of a region is related to its ability to withstand or recover from an economic shock, rather than whether the effect of the shock hits innovation performance. Similarly, our analysis considers the extent to which innovation capacity (as measured by the Regional Innovation Scoreboard) is associated with resistance to an economic shock or recovery in the short-term, rather than resilience as longer-term reorientation and renewal.

The data available at regional level is considerably less than at national level and varies across countries. This means that the 2012 RIS is constructed on the basis of 55 NUTS 1 regions and 135 NUTS 2 regions, giving a total of 190 datapoints. Owing to the data limitations, regions are ranked using cluster analysis and assigned to one of four classes. Regions which perform above average are classed as Innovation Leaders, whilst those which score close to the average are termed Innovation Followers. Regions which score less than the average are classed as Moderate Innovators, whilst those with scores significantly below the average are termed Modest Innovators. These classifications are primarily a means of labelling the four clusters; there is nothing in the data that suggests that the leading regions lead in any real manner or those that are labelled followers actually follow the actions of others. In total, 41 regions were classed as Innovation Leaders, 58 as Innovation Followers, 39 as Moderate Innovators and 52 as Modest Innovators across 24 countries (22 EU countries plus Norway and Switzerland) at the time of the economic crisis (European Commission 2012). Six EU countries (Cyprus, Estonia, Latvia, Lithuania, Luxembourg and Malta) are not included in the RIS 2012 analysis.

Using RIS 2012 as a basis for our comparative assessment, we identified the resilience group for each of the 190 regions using the database of NUTS 1 and NUTS 2 
Table 2 Distribution of regions across resilient states and innovation categories

\begin{tabular}{|c|c|c|c|c|c|c|c|c|c|}
\hline & \multicolumn{2}{|c|}{ Resistant } & \multicolumn{2}{|c|}{ Recovered } & \multicolumn{2}{|c|}{$\begin{array}{l}\text { Not Recovered: } \\
\text { Upturn }\end{array}$} & \multicolumn{2}{|c|}{$\begin{array}{l}\text { Not Recovered: } \\
\text { Downturn }\end{array}$} & \multirow{2}{*}{$\begin{array}{l}\text { Total } \\
\text { No. }\end{array}$} \\
\hline & No. & $\%$ & No. & $\%$ & No. & $\%$ & No. & $\%$ & \\
\hline Innovation leader & 6 & 17.1 & 16 & 45.7 & 12 & 34.3 & 1 & 2.9 & 35 \\
\hline Innovation follower & 4 & 6.8 & 12 & 20.3 & 27 & 45.8 & 16 & 27.1 & 59 \\
\hline Moderate innovator & 1 & 2.5 & 6 & 15.0 & 19 & 47.5 & 14 & 35.0 & 40 \\
\hline Modest innovator & 7 & 13.5 & 3 & 5.8 & 17 & 32.7 & 25 & 48.1 & 52 \\
\hline Total & 18 & 9.7 & 37 & 19.9 & 75 & 40.3 & 56 & 30.1 & 186 \\
\hline
\end{tabular}

results obtained previously. In practice, this was only possible for 186 regions owing to data limitations with regard to Switzerland. This found that 18 regions had withstood the economic crisis and not experienced a downturn in employment since the early 2000s, whilst 37 regions had experienced a fall in employment associated with the crisis, but had recovered to their pre-crisis peak by 2011. On this basis, it appears that some 55 regions $(29.6 \%)$ were resilient in the face of the economic crisis. Set against this, of the 131 regions that were not resilient to the crisis, 75 had begun to experience a recovery in employment numbers by 2011 , although they had yet to regain peak employment levels, whilst 56 were still experiencing falling levels of employment.

The variable speed and geography of the economic crisis is revealed by this approach (and discussed in more detail in Sensier et al. 2016). The first signs of the emerging crisis were revealed in 2006, with the effects of the economic shock gathering pace through 2007 and 2008. Regions in Bulgaria, Germany, Hungary, Italy, Portugal, Romania and the UK were amongst the first to experience employment declines. By 2009, a fully fledged crisis had engulfed European economies. During 2009, however, the first signs of recovery were also apparent, with regions in Austria, Belgium, Germany, France, Hungary, Malta, Sweden and the UK all having reached their trough employment level. Whilst the crisis therefore exhibited a variable speed and geography, most economies experienced the onset of crisis in 2007-2008, although there were clearly some with an earlier onset. Rates of recovery also varied.

Taking the resilience state of each territorial unit under analysis allows us to assess the proportion of each within each regional innovation cluster (Table 2). Table 2 illustrates that although there is no simple relationship between regions with a strong innovation performance and their observed resilience to the economic crisis, there does appear to be a positive association between regions with a stronger level of innovation and their resilience to the crisis.

This association is strengthened when we consider the extent to which resilience of regions in the different innovation clusters are under- or overrepresented relative to their incidence across the population of regions as a whole. This allows us to consider the extent to which a particular innovation cluster might be more closely associated with particular resilience states. If innovation performance has no effect on resilience, then we would expect a value of 100 to be recorded. The higher the value, the greater the extent to which that resilience state is overrepresented. In contrast, values of less 
Table 3 Over- or underrepresentation of regions

\begin{tabular}{lllll}
\hline & Resistant & Recovered & $\begin{array}{l}\text { Not recovered } \\
\text { (upturn) }\end{array}$ & $\begin{array}{l}\text { Not recovered } \\
\text { (no upturn) }\end{array}$ \\
\hline Innovation leader & 177.1 & 229.8 & 85.0 & 9.5 \\
Innovation follower & 70.1 & 102.2 & 113.5 & 90.1 \\
Moderate innovator & 25.8 & 75.4 & 117.8 & 116.3 \\
Modest innovator & 139.1 & 29.0 & 81.1 & 159.7 \\
Total & 100 & 100 & 100 & 100 \\
\hline
\end{tabular}

than 100 signal that a particular innovation cluster is less associated with a particular resilience state than would be expected given the overall distribution. Values close to or equal to 100 suggest that a particular innovation cluster is neither more nor less likely to have influenced the distribution of resilience states.

From Table 3, it is apparent that regions that were categorized as Innovation Leaders at the time of the crisis were significantly more likely to have resisted or recovered from the crisis than might normally have been anticipated. Regions that were categorized as Innovation Followers were more likely to be found in the Recovered or the Not Recovered: Upturn state, but in practice this level of innovation does not appear to have a strong influence on resilience to the economic crisis. Regions that were categorized as Moderate Innovators were more likely to be found in the Not Recovered states (either in upturn or still in downturn). Regions that were Modest Innovators were largely to be found in the Not Recovered resilience states, although there was also a significant overrepresentation of regions that were Resistant to the crisis.

From Table 3, it appears that the stronger the innovation performance of a region, the more likely it is to be associated with a resilient outcome in the face of the economic crisis and the less likely it was to be in a non-recovered (or non-resilient) category. For those with weaker innovation performance, the opposite is broadly true, although there is an anomaly in the hypothesis that levels of innovation are positively associated with resilience outcomes in the overrepresentation of regions categorized as Modest Innovators found in the Resistant state. On further analysis, this is entirely due to the performance of Polish regions in the face of the economic crisis. Poland was one of the few economies to largely withstand, or resist the crisis, for reasons that remain to be fully explored (Sensier et al. 2016). To control for the possibility that the performance of a small number of Polish regions might be skewing the results, we reran the analysis omitting all Polish regions. The results are reported in Table 4, which now more clearly demonstrates the significance of strong innovation performance to resilience to the economic crisis and the negative effects of low levels of innovation performance.

\section{Resilience and innovation: discussion}

Our results indicate that regions with greater innovation capacity and performance were more likely to resist the 2007-2008 economic crisis in Europe or to recover 
Table 4 Regional outcomes excluding Polish regions

\begin{tabular}{lllll}
\hline & Resistant & Recovered & $\begin{array}{l}\text { Not recovered } \\
\text { (upturn) }\end{array}$ & $\begin{array}{l}\text { Not recovered } \\
\text { (no upturn) }\end{array}$ \\
\hline Innovation leader & 291.4 & 222.0 & 83.3 & 8.8 \\
Innovation follower & 115.3 & 98.8 & 111.4 & 83.8 \\
Moderate innovator & 0 & 74.7 & 118.3 & 111.0 \\
Modest innovator & 0 & 13.1 & 78.8 & 200.5 \\
Total & 100 & 100 & 100 & 100 \\
\hline
\end{tabular}

quickly from it. This gives credence to the earlier assertions that innovation underpins resilience to economic shocks and provides the first empirical evidence of a positive link with resistance and recovery. This is an exploratory analysis however, and whilst it provides some valuable insights into the importance of innovation and its role in regional resilience to shocks, it raises further questions about the empirical challenges of operationalizing these concepts and measuring their relationship. This analysis also provides further insights into existing evolutionary theorizing of the relationship between innovation and resilience.

Our analysis is based upon a measure of innovation within regions which is relatively broad and measures factors enabling innovation capacity, as well as firm-level activities and outputs. Indicators in the Regional Innovation Scoreboard enable a consideration of the wider context in which change occurs. In no small part, this is aided by the inclusion of measures that incorporate notions of experiential learning - the doing, using and interacting approach — and do not overly privilege science and technologyled measures. It suggests therefore the importance of an agile innovation system which is not only producing new goods and services, but also embracing constant feedback, adaptation and learning. However, whilst the Regional Innovation Scoreboard has its strengths, it is less able to capture the adaptive behaviour of firms over time. In part this is due to difficulties of comparing different editions of the Community Innovation Survey, owing to methodological and definitional changes in the construction of the survey over time. This limits our ability to assess how firms across different European regions responded to the crisis over a longer period of time and so contribute to patterns of regional reorientation. Further work decomposing the common elements of innovation strength which appear in resilient regions would also enable further understanding of some of the critical sources of adaptability at play.

We must also acknowledge that whilst our results provide strong support for the role of innovation in promoting resistance and recovery, there are some exceptions to this, notably a number of Polish regions. Understanding the reasons for this will require further exploration, but is likely to reflect the existence of a variety of determinants of resilience, some of which may play a more important role than others in different spatial contexts (Martin and Sunley 2015; Sensier et al. 2016). Innovation is an important part of the resilience story, but it is not the only part. Our results provide further evidence of the fact that there is no 'magic bullet' in the pursuit of economic resilience. The evidence from the Regional Innovation Scoreboard, combined with our own analysis 
of resilience outcomes, also raises questions as to the relative influence of regional and national characteristics in shaping regional capacities to resist and recover from shocks. Regions are part of larger economic systems with which they share growth and decline. Thus, the macroeconomic conditions of nations and the limitations imposed by participation in supranational monetary union may have considerable influence on regional growth trajectories (Capello 2013). This warrants further research.

Our analysis also suggests that the role of innovation extends beyond the provision of initial or underlying structural, and market strengths in a region which may help provide some crisis-preparedness or fit to the changing economic environment. It suggests that a region's innovative capacity also fundamentally reflects the capacity of agents within the region to learn from previous shocks, to respond quickly and effectively when a crisis hits and to make choices which enhance their capacity to cope. This aligns with the theorizing of regional economies as complex adaptive systems comprised of multiple groups of agents who are continually learning and adapting to changes in their external environment. Innovation, particularly when measured broadly to embrace the wider regional innovation propensities and capacities, reflects the adaptive capacities of agents within the region. Innovative firms have greater acquired or potential knowledge of the changing economic environment. As such, they may be more likely to exhibit the skills and techniques that will enable them to respond quickly and adapt when a shock hits by targeting new markets or shifting resources around to buffer any changes. It is also possible that firms in innovative regions are positioned higher up the value chain and so have more room for manoeuvre and more opportunity to either bring goods back in house or to shift low value activity to others.

Our findings thus have insights for evolutionary theorizing on innovation and resilience and their relationship. In particular, our results suggest that innovation's role in resilience is not simply one that can be construed as a purely technological or disruptive process. Our results suggest that innovation may be a more iterative, adaptive and continual process and a key enabler of adaptability in short-term crisis shock preparedness and recovery processes, as well as in longer term, more transformative renewal processes. In this manner, the resilience outcomes observed appear to be more aligned to those described by complex adaptive systems thinking than Schumpeterian notions of creative destruction. Innovative regions are continually adapting to changes in their economic environment, with these changes then in turn provoking further rounds of innovation and change. In giving further consideration to the relationship between innovation and regional economic resilience, it may be that we should lend greater weight to exploring the dynamic, nature of these adaptive processes within regions, the interactions between them and the patterns they form. Our evidence suggests innovation's role may certainly be more continuous and iterative rather than cyclical, which speaks to the critical point made by Arthur et al. (2005) that the patterns in complex systems may never be finished, but rather are more openended. These interaction and patterns are likely to be challenging to operationalize and explore empirically.

This finding is further reinforced when the potentially wider context within which region innovation capacity is conducted and nurtured is considered-factors which are not fully captured in the Innovation Scoreboard. The broader and developing literature on regional innovation systems highlights a number of salient themes including, 
firstly, the importance of the economic and institutional environment within which firms operate for their ability to innovate and to make effective use of innovation. Built on evolutionary theories of economic and technological change, the regional systems of innovation literature conceptualizes innovation as an evolutionary and social process, strongly shaped by contingencies of context and place (Asheim and Gertler 2004). Innovation is stimulated and influenced by many actors and factors, both internal and external to the firm. The social aspect of innovation refers to the collective learning process between several departments of a firm as well as to external collaborations with other firms and knowledge providers. Variations in a region's institutional qualities and environment, the relationships and connections between its actors and other relevant economic capacities mean that innovation is highly localized and is a territorially embedded, rather than placeless, process. This gives rise to strong differences in levels of innovation between places, reflecting differential capacities to generate knowledge and also, critically, to diffuse, absorb and make effective use of it (Cooke et al. 2000; Cooke 2012; Rodríguez-Pose 2013). Regions with weak institutions often exhibit unfavourable research and innovation systems. These are systems characterized by organizational thinness, lock-in to declining sectors and out-dated technologies, fragmentation (which inhibits networking and knowledge exchange), and a weak capacity to respond to and effect change (Tödling and Trippl 2005; Strambach and Klement 2012; Weber and Rohracher 2012). Strong innovation systems are likely to be those characterized by stronger collective institutions of governance and knowledge exchange and, in turn, more effective capacities for positive short-term reaction and response. Furthermore, high rates of innovation and global search are likely to be most effective in supporting regional development and resilience where they are deployed in a regional economic system which has some inertia or stability and thus a capacity to effectively apply new innovations within relatively stable knowledge structures (Martin and Sunley 2007).

Secondly, the innovation systems literature asserts that innovation is itself a nonlinear, complex and broad process which does not simply stretch from research and development through to commercialization. Neither is it reducible to technological advancement in firms and the development of new or improved products, processes and services. It may also include innovations in organizational structures and marketing and is understood to be more lateral and pervasive in contemporary economies than vertically integrated, sectoral or even cluster based (Asheim et al. 2011). Thus, firms increasingly have to acquire new knowledge from external sources and from more diverse knowledge networks which transcend industries, sectors and the common taxonomies of high or low technology (Smith 2000). In short, in today's complex economies, no one actor or group of actors is omniscient or has the capacity (or indeed knowledge) to influence all the conditions that affect them (Moore and Westley 2011). Thus, an effective entrepreneurial search or discovery process places a premium on the synthesis of entrepreneurial knowledge from a wide range of individuals and organizations, and is a process of trial and error, and indeed, of success and failure (Hausmann and Rodrik 2003; Foray et al. 2011). As such, the innovation that may enable resilience in terms of resistance and recovery may not necessarily be the disruptive, technological kind. Most innovation is 'a continuous process of incremental problem solving rather than one of grandiose "breakthroughs" (Bahadur and Doczi 2016, p. 8). 
This continuous iterative process lies at the heart of evolutionary economic geography, but there are clearly limitations from our observation of the patterns here. In particular, there are further questions to be addresses as to what they reveal about the evolutionary dynamics for regions in the future, i.e. are the more resilient regions here likely to exhibit greater capacity for long-term reorientation and renewal? Are we picking up early signs of creative destruction? It is only now, some 8 years after the crisis that we may be able to detect these changes across European regions. As such, there is much further research to be done in how, if at all, regions have undergone more transformative change since the 2007-2008 shock and how this relates to early signs of resilience. However, we should not underestimate the challenges of doing so. Understanding dynamic adaptation in regions is difficult from large-scale cross-comparative study and as such, there is further work to be done in exploring whether certain regions with definable characteristics exhibit similar regional economic trajectories and patterns. Furthermore, there is a need for further reflection on the relationships, if any, between the role of innovation in resistance and recovery and how this relates to reorientation and renewal. To what extent is one constitutive of the other or are they inherently linked in some other way? What we can say is that resilience as recovery and resistance should not necessarily be interpreted as signalling very little has changed, i.e. that there has simply been a rapid bounce-back to some preexisting employment or economic activity levels. Whilst the employment level may have recovered to a similar pre-crisis point, the ongoing innovation activity in the region suggests that the region's circumstances and capacities are likely to have changed considerably.

\section{Conclusions}

Our results demonstrate that the capacity for innovation within a region is strongly related to its propensity to be resilient to economic shocks. Those regions that proved able to resist the 2007-2008 economic crisis across Europe tended to have the highest levels of innovation capacity and performance. Significantly, our work also demonstrates quite conclusively that those regions which were least able to respond to the economic crisis had the lowest levels of innovation capacity. Whilst this relationship has been previously suggested, our work demonstrates this empirically. However, our work also demonstrates that whilst the level of innovation capacity is an important explanation for why some regions were more resilient to the economic crisis than others, it is not the only explanation, as the case of Poland illustrates. Further work to understand the particularities of the Polish experience is strongly warranted, as is further work to unpack the relative importance of other factors in shaping economic resilience.

The reasons for the stronger resilience of more innovative regions also merit deeper exploration. Much of the existing literature focuses on structural factors and longer-term transformative resilience, and specifically, the role that technological innovation plays in creating opportunities for the development of more diverse regional economies characterized by new or related paths of development. However, existing literature suggests that for the broader system (the organization, the community or 
society) to be resilient, it is not enough to innovate in technological terms. Society needs to build the capacity for absorbing innovation. Our use of the Regional Innovation Scoreboard, which is a more capacious measure of innovation capacity, supports this. Crucially, this suggests that it is not only the deliberate acquisition of knowledge that marks out human systems and makes them adaptive, but it is also the purposive deployment of that knowledge. However, further work is clearly needed, not least in developing an even richer measure of innovation capacity which captures the contextual and institutional factors discussed above.

This signals an important message for policy makers. Whilst innovation does indeed build economic resilience, this is unlikely to be achieved simply through support for R\&D activities and science and technology-led innovations. For economies to have the capacity to respond to shocks, enabling resistance or recovery, policies need to also promote the capacity for doing, using and interacting. Resilient economies are likely to have agile innovation systems which promote new combinations of activity, where organizations are willing to accept risks, and where adaptability is built into the behaviour and responses of key actors in the region. The more choices that are available when a shock hits, the greater the probability that one of these choices will provide a positive and effective route through the crisis and indeed a new path beyond it. Innovation is thus a mindset and a capacity as much as an outcome of firm performance. Innovative regions may be better equipped to respond because they exhibit a protean attitude to the dynamics of and need for change.

The innovation metric used here is broader than simply a measure of technological innovation and embraces indicators of both innovation performance and capacity or the attitudes of firms and other agents in the regional economy to shocks and change. The positive relationship between this metric and short-term crisis resistance and recovery suggests that it may be in these more agentic behaviours and relationships that the answer lies. Innovation capacity appears to influence both adaptation over the longterm and short-term adaptability and may be reflective and indeed constitutive of wider behaviours and attitudes to change. Innovation may be a critical system dynamic that crucially shapes how quickly and effectively agents adapt to their changing economic environment.

Evolutionary thinking reminds us that the relationship between innovation and resilience is not a simple cause and effect. There are complex co-evolutionary dynamics at work that make simple empirical measurement challenging and results subject to caution. Furthermore, context matters. Whilst we can establish regularities in complex systems and gain understanding as to how the range of outcomes emerge from different components and mechanisms coming together, the complexities of context and interactions will inevitably lead to different outcomes in different regional economies (Zellner and Campbell 2015). CAS thinking thus alerts us to the need to emphasize future outcomes in probabilistic rather than deterministic terms, which builds on the traditional Schumpetarian notion of innovation as an agent of change.

Having demonstrated the relationship between innovation and economic resilience, our results open up questions on the nature of this relationship. In the evolutionary economic geography literature, there is increasing understanding that resilience is a complex, multi-dimensional property of regional economic systems. Innovation capacities contribute one part of a region's capacity to withstand or quickly recover from 
economic shocks. However, in embracing both a capacity to weather economic shocks as well as to adapt and transform, resilience also has a temporal dimension. Whilst a regional economy may cope well with an economic shock and thus demonstrate resilience in the short-term, this does not necessarily mean it will be resilient to future economic shocks or have the capacity to improve its economic and social outcomes over the longer term (Bristow and Healy 2015). Conversely, regions that did not prove to be resilient to the crisis may prove more able to transform their economies over the longer term. Our work does not yet shed light on this, and the relationship between resilience in terms of resistance and recovery and reorientation and renewal remains to be explored.

Our results have gone some way to address Sunley's observation on the lack of empirical evidence as to whether more innovative regions are likely to be more resilient. However, as we show, the relationship between greater levels of innovation and resilience remains complex and merits further research.

Open Access This article is distributed under the terms of the Creative Commons Attribution 4.0 International License (http://creativecommons.org/licenses/by/4.0/), which permits unrestricted use, distribution, and reproduction in any medium, provided you give appropriate credit to the original author(s) and the source, provide a link to the Creative Commons license, and indicate if changes were made.

\section{References}

Aldrich DP, Meyer MA (2014) Social capital and community resilience. Am Behav Sci. doi:10.1177/ 0002764214550299

Arthur B, Durlauf S, Lane D (2005) The economy as an evolving complex system II. Addison-Wesley, Reading

Asheim B, Gertler M (2004) Understanding regional innovation systems. In: Fagerberg J, Mowery D, Nelson $\mathrm{R}$ (eds) Handbook of innovation. Oxford University, Oxford

Asheim BT, Smith HL, Oughton C (2011) Regional innovation systems: theory, empirics and policy. Reg Stud 45(7):875-891

Bahadur A, Doczi J (2016) Unlocking resilience through autonomous innovation. Working paper, Overseas Development Institute, London

Beinhocker ED (2007) The origin of wealth: evolution, complexity and the radical remaking of economics. Random House, London

Berkes F, Folke C (1998) Linking social and ecological systems: management practices and social mechanisms for building resilience. Cambridge University Press, Cambridge

Boschma R (2015) Towards an evolutionary perspective on regional resilience. Reg Stud 49(5):733-751

Boschma R, Minondo A, Navarro M (2013) The emergence of new industries at the regional level in Spain. A proximity approach based on product-relatedness. Econ Geogr 89:29-51

Bristow G, Healy A (2014) Regional resilience: an agency perspective. Reg Stud 48(5):923-935

Bristow G, Healy A (2015) Crisis response, choice and resilience: insights from complexity thinking. Camb J Reg Econ Soc 8(2):241-256

Bruijn P, Lagendijk A (2005) Regional innovation systems in the Lisbon strategy. Eur Plan Stud 13(8):11531172

Capello R (2013) Regional economics. Routledge, Abingdon

Capello R, Caraglui A, Fratesi U (2015) Spatial heterogeneity in the costs of the economic crisis in Europe: are cities sources of regional resilience? J Econ Geogr. doi:10.1093/jeg/lbu053

Castaldi C, Frenken K, Los B (2013) Related variety, unrelated variety and technological breakthroughs, an analysis of U.S. state-level patenting. Papers in evolutionary economic geography no. 13.02. Utrecht University, Utrecht 
Coad A (2009) The growth of firms: a survey of theories and employment evidence. Edward Elgar, Cheltenham

Cooke P (2011) Transition regions: regional-national eco-innovation systems and strategies. Prog Plan 76(3):106-134

Cooke P (2012) Complex adaptive innovation systems: relatedness and transversality in the evolving region. Routledge, London

Cooke P, Eriksson A (2011) White spaces innovation in Sweden: innovation policy for exploring the adjacent possible. VINNOVA, Sweden

Cooke P, Boekholt P, Todtling F (2000) The governance of innovation in Europe. Pinter, London

Cooke P, Parrilli MD, Curbelo JL (eds) (2012) Innovation, global change and territorial resilience. Edward Elgar, Cheltenham

Cowell M, Gainsborough J, Lowe K (2016) Resilience and mimetic behaviours: economic visions in the Great Recession. J Urban Aff 38(1):61-78

Crescenzi R (2011) A spatial perspective on innovation and economic growth. In: Crescenzi R, RodriguezPose A (eds) Innovation and regional growth in the European Union. Springer, Berlin

D'Agostino G, Scarlato M (2015) Innovation, socio-institutional conditions and economic growth in the Italian regions. Reg Stud 49(9):1514-1534

Davies S (2011) Regional resilience in the 2008-2010 downturn: comparative evidence from European countries. Camb J Reg Econ Soc 4(3):369-382

Diodato D, Weterings ABR (2014) The resilience of regional labour markets to economic shocks: exploring the role of interactions among firms and workers. J Econ Geogr 15(4):723-742

Dubé J, Polèse M (2016) Resilience revisited: assessing the impact of the 2007-09 recession on 83 Canadian regions with accompanying thoughts on an elusive concept. Reg Stud 50(4):615-628. doi:10.1080/ 00343404.2015 .1020291

European Commission (2012) Regional Innovation Scoreboard 2012. European Commission, Brussels

European Commission (2014) Regional Innovation Scoreboard 2014. European Commission, Brussels

Foray D, David PA, Hall BH (2011) Smart specialisation: from academic idea to political instrument, the surprising career of a concept and the difficulties involved in its implementation. METI Working paper 2011-001 Ecole Poytechnique Federal de Lausanne

Frenken K, van Oort FG, Verburg T (2007) Related variety, unrelated variety and regional economic growth. Reg Stud 41:685-697

Grabher G, Stark D (1997) Organising diversity: evolutionary theory, network analysis and postsocialism'. Reg Stud 31:533-544

Gunderson L, Holling CS (2002) Panarchy: understanding transformations in human and natural systems. Island Press, Washington

Hadjimichalis C, Hudson R (2014) Contemporary crisis across Europe and the crisis in regional development theories. Reg Stud 48(1):208-218

Hausmann R, Rodrik D (2003) Economic development as self-discovery. J Dev Econ 72(2):603-633

Hudson R (2010) Resilient regions in an uncertain world: wishful thinking or a practical reality? Camb J Reg Econ Soc 3(1):11-25

Isaksen A, Trippl M (2014) Regional industrial path development in different regional innovation systems: a conceptual analysis CIRCLE Working papers, Lund

Jensen MB, Johnson B, Lorenz E (2007) Forms of knowledge and modes of innovation. Res Policy 36:680693

Martin R (2012) Regional economic resilience, hysteresis and recessionary shocks. J Econ Geogr 12(1):1-32

Martin R, Sunley P (2006) Path dependence and regional economic evolution. J Econ Geogr 6:395-437

Martin R, Sunley P (2007) Complexity thinking and evolutionary economic geography. J Econ Geogr 7:573-602

Martin R, Sunley P (2012) Forms of emergence and the evolution of economic landscapes. J Econ Behav Organ 82(2-3):338-351

Martin R, Sunley P (2015) On the notion of regional economic resilience: conceptualisation and explanation. J Econ Geogr 15(1):1-42

Moore M-L, Westley F (2011) Surmountable chasms: networks and social innovation for resilient systems. Ecol Soc 16(1):5

Moulaert F, Sekia F (2003) Territorial innovation models: a critical survey. Reg Stud 37:289-302

Navarro M, Gibaja JJ, Bilbao-Osorio B, Aguado R (2009) Patterns of innovation in the EU-25 regions: a typology and policy recommendations. Environ Plan C Gov Policy 27:815-840 
NESTA (2009) The Vital 6\%: How high-growth innovative businesses generate prosperity and jobs. Research summary, NESTA, London, October 2009

Pike A, Dawley S, Tomaney J (2010) Resilience, adaptation and adaptability. Camb J Reg Econ Soc 3:71-84 Rodríguez-Pose Andrés (2013) Do institutions matter for regional development? Reg Stud 47(7):1034-1047

Roper S, Xia H (2014) Innovation, innovation strategy and support. Enterprise Research Centre (ERC) Research paper, February 2014, Enterprise Research Centre

SC6 Advisory Group (2014) Resilient Europe, Societal Challenge 6: Europe in a changing world—inclusive, innovative and resilient societies. Advisory Group on Societal Challenge 6. Recommendations to the European Commission. http://ec.europa.eu/programmes/horizon2020/sites/horizon2020/files/ SC6-Advisory-Group\%20report\%20for\%202016-2017.pdf. Last accessed 20 May 2016

Schumpeter JA (1939) Business cycles: a theoretical, historical and statistical analysis of the capitalist process. McGraw-Hill, New York

Schumpeter JA (1942) Capitalism, socialism and democracy. McGraw-Hill, New York

Sensier M, Bristow G, Healy A (2016) Measuring regional economic resilience across Europe: operationalising a complex concept. Spat Econ Anal 11(2):1-44

Simmie J (2014a) Evolutionary growth theory and resilience in UK cities: re-invention, replication, recession and recovery. Technical Report, Oxford Brookes University

Simmie J (2014b) Regional economic resilience: a schumpeterian perspective. Raumforsch Raumordn $72: 103-116$

Simmie J, Martin RL (2010) The economic resilience of regions: towards an evolutionary approach. Camb J Reg Econ Soc 3(1):27-44

Smith K (2000) Innovation as a systemic phenomenon: rethinking the role of policy. Enterp Manag Stud 1(1):73-102

Storper M (2011) Why do regions develop and change? The challenge for geography and economics. J Econ Geogr 11:333-341

Strambach S, Klement B (2012) Cumulative and combinatorial micro-dynamics of knowledge: the role of space and place in knowledge integration. Eur Plan Stud 20:1843-1866

Sunley P (2013) Innovation. Global change and territorial resilience. Reg Stud 47(4):644-645

Tödling F, Trippl M (2005) One size fits all? Towards a differentiated regional innovation policy approach. Res Policy 34:1203-1219

UK BIS (Department for Business, Innovation and Skills) (2014a) Our plan for growth: science and innovation. UK BIS, London

UK BIS (Department for Business, Innovation and Skills) (2014b) Innovation, skills and performance in the downturn: an analysis of the UK innovation survey 2011. UK BIS, London

Weber KM, Rohracher H (2012) Legitimising research, technology and innovation policies for transformative change. Combining insights from innovation systems and multi-level perspectives in a comprehensive 'failures' framework. Res Policy 41:1037-1047

Wolfe DA (2014) Introduction to the dynamics of innovation in city-regions. In: Wolfe DA (ed) Innovating in urban economies: economic transformation in Canadian city-regions. University of Toronto Press, Toronto, pp 3-32

Wolfe DA, Gertler M (2016) Growing urban economies: innovation, creating and governance in Canadian city-regions. University of Toronto Press, Toronto

Xiao J, Boschma R, Andersson M (2016) Industrial diversification in Europe: the differentiated role of relatedness. Papers in Evolutionary Economic Geography \#16:27, Utrecht University

Zellner M, Campbell Scott D (2015) Planning for deep-rooted problems: what can we learn from aligning complex systems and wicked problems? Plan Theory Pract 16(4):457-478 